\title{
Variability of Polyphenols, Antioxidant Activity and UFLC Phenolic Acid Profiles of Different Sorghum Genotypes
}

\author{
Ranga Bhukya, Ratnavathi V. Chamarthy", Shobha Ediga, Aruna C. Reddy, Suresh Babu Marriboina, Vilas A. Tonapi
}

ICAR-Indian Institute of Millets Research, Rajendranagar, Hyderabad-500 030, Telangana, India

DOI: $\underline{10.36348 / \mathrm{sijb} .2020 . \mathrm{v} 03 \mathrm{i} 05.001}$

| Received: 20.04.2020 | Accepted: 27.04.2020 | Published: 07.05.2020

*Corresponding author: Ratnavathi V. Chamarthy

\section{Abstract}

Sorghum stands as the fifth most valuable global cereal crop, widely grown in semi-arid and arid regions of the world. This present investigation details the variability of polyphenols, scavenging activity in terms of ascorbic acid equivalents of 60 grain sorghum genotypes collected from various countries and were grown at Indian Institute of Millet Research fields which include 38 white, 15 red, and 7 brown pericarp grain sorghum genotypes. Polyphenols range from 575.05 to $3161.87 \mathrm{mg}$ GAE. $\mathrm{kg}^{-1}, 888.33$ to $4230.14 \mathrm{mg}$ GAE. kg ${ }^{-1}, 1274.91$ to $2885.72 \mathrm{mg} \mathrm{GAE} . \mathrm{kg}^{-1}$ in white, red and brown sorghum genotypes respectively. The DPPH radical scavenging activity ranges from 555.74 to $6058.80 \mathrm{mg}$ AAEQ. $\mathrm{kg}^{-1}$, 1190.19 to $6549.59 \mathrm{mg}$ AAEQ. $\mathrm{kg}^{-1}$ and 2174.43 to $5494.40 \mathrm{mg}$ AAEQ. $\mathrm{kg}^{-1}$, in white, red and brown sorghum grain genotypes respectively. Ultra fast liquid chromatography (UFLC) profiling of phenolic acids done in phenolic extracts of red, white and brown sorghum genotypes showed that analytes were derivatives of benzoic acid and cinnamic acid. Total of eleven different phenolic acids were identified, of which ferulic acid is highly expressed in white and red sorghum genotypes only.

Keywords: Totalphenols, Scavenging activity, Polyphenols, Sorghum, Antioxidants, phenolic acid profiling.

Copyright @ 2020: This is an open-access article distributed under the terms of the Creative Commons Attribution license which permits unrestricted use, distribution, and reproduction in any medium for non-commercial use (NonCommercial, or CC-BY-NC) provided the original author and source are credited.

\section{INTRODUCTION}

Free radicals are derived form of oxygen and nitrogen, they are effective agents of oxidative stress related to pathogenesis of various degenerative diseases. Oxidative stress reflects an imbalance in favor of free radicals as a result of increase in production or depletion of antioxidant moieties. The Oxidative stress is considered to be the contributory factor in neurodegenerative disorders such as Alzheimer's and Parkinson's diseases and also initiates and promotes the progression of a number of chronic diseases such as diabetes, cancer, cardiovascular diseases, cataract and inflammation. Therefore the intake of phenolic compounds is thought to have more health benefits such as reducing oxidative stress and providing antiinflammatory, anti -carcinogenic properties [1].

Awareness on natural antioxidants and usage in food products have increased recently because of uncertainty about long term usage of artificial antioxidants such as Butylated hydroxytoluene (BHT) and Butylated hydroxyanisole (BHA). In addition to their long term protection and ability to enhance food quality, these natural antioxidants can also act as good scavengers of free radicals that are produced in biological systems and provide additional health benefits to consumers. Experiments have suggested that these compounds showed anti radical property thereby involved in various biological functions [2]. Recent studies have suggested the role of plant phenolic compounds as natural antioxidants in foods. Several experimental works have drawn co-relationship between phenolic content and antioxidant property in millet extracts and in processed foods [3]. Some authors found a co-relationship between polyphenols and scavenging activity in plant extracts, while some could not establish any relationship. Cereals contain wide variety of phytochemical agents such as polyphenols, tannins and flavonoids. Among all cereals, maize and red sorghum were found to have high polyphenolic content [4]. Fourteen commonly consumed fresh fruits and ten dry fruits were studied [5] indicated that antioxidant activity and TPC contents of both fresh and dry fruits showed marked variation.

Sorghum bicolor L. Moench is the fifth most important cereal crop in the world after wheat, rice, maize, and barley. Sorghum is grown in semi-arid regions and ranks third in terms of production value, after maize and rice, with a share of $12 \%$ on total 
cereal production value (Food and Agriculture Organization of the United Nations Economic and Social Department [6]. In India, the type of sorghum grown is mostly white coloured grain and the white variety of sorghum is widely consumed as staple food and fodder whereas in other countries such as Japan and USA, white sorghum is used only to a small extent and coloured sorghum is grown and used for human and animal consumption.

The phenolic compounds which had the highest antioxidant activity in Shawaya and IS11316 were reported as catechin, 1-O-cafferolglycerol-Oglucoside, taxifolin and pentahydroxyflavanone-(3->4)catechin-7-O-glucoside [7]. Further the sorghum grain has reported to contain flavonoids, anthocyanins, and tannins. sorghum grain phytochemicals gained lot of interest due to their scavenging activity, nutraceutical property, anti-obese property, preservative property and other health benefits. Hence, sorghum polyphenols could serves as good therapeutic agents [8].

Earlier [9] have compared the scavenging activities of sorghum and sorghum products ; they had studied the phenols and scavenging activities of white sorghum in different sub-solvent fractions. In the present study, we report the polyphenols and in-vitro scavenging activity of different coloured sorghum flour. The objectives undertaken in the present study were characterization and identification of sorghum genotypes with high scavenging activity, type of phenolic acids and phenolic content and their association in considering it as a functional food.

\section{MATERIALS AND METHODS Chemicals}

UFLC, AR grade solvents and Millipore distilled water (Merck-Millipore, Synergy, UV plus) were used in the extraction and analysis. The chemicals 1,1-Diphenyl-2-picrylhydrazine (DPPH), Ascorbic acid, Phenolic acid standards were procured from SigmaAldrich, U.S.A. Folin-Ciocalteau's reagent, Sodium Carbonate, Hydrochloric acid, Gallic acid (3, 4, 5Trihydroxy benzoic acid) were purchased from Sisco Research laboratories, Mumbai, India. HPLC grade Methanol, Phosphoric acid, and acetonitrile were obtained from Merck India Pvt ltd, Mumbai. Phenolic acid stand UFLC standard compounds were purchased from sigma-Aldrich. All the chemicals were of analytical grade.

\section{Plant Material}

Sorghum genotypes (60) were evaluated in augmented design during rabi which include 38 genotypes with white colour pericarp, 15 with red colour pericarp and 7 with brown colour pericarp. These were collected from germplasm pool grown in medium to light soils in the experimental farms of Indian Institute of Millet Research (formerly Directorate of sorghum research), located at
Rajendranagar, Hyderabad, India. The material was sown in three blocks, each with 20 entries. Two elite genotypes, 296 B and C 43 were used as checks in each block. Each genotype was grown in a single line of $5 \mathrm{~m}$ length. The material includes germplasm lines belonging to different races from different countries.

Based on the grain pericarp colour genotypes were categorized into three groups, white, red and brown colour grain sorghum genotypes. White color grain sorghum inculudes 27B, 296B, 463B, 7B, AKMS14B, AKR150, AKR354, C43, CSV13, CSV15, IC345194, IC305903, IC305923, I12, IMS9B, IS33648, IS40751, IS4372, RS627, RS673, SPV1258, SPV1293, SPV1471, SPV1606, SPV1616, SPV1731, SPV1732, SPV1733, SPV1734, SPV1750, SPV1760, SPV1775, SPV462, SPV459, SPV711, SPV933, IS18035(originated in India), IS31681( Algeria). Red color sorghum grain and its origin includes IS1212 (China), IS12706, IS20743 ( USA), IS16151 ( Cameroon), IS20298 (Nigeria), IS23514 (Ethiopia), IS2389, IS3158 ( South Africa), IS28141, IS28313, IS12735 ( Republic of Yemen), IS29950 (Zimbabwe), IS30538 (Republic of korea), IS4060 (India), IS29241 (Swaziland). Brown color sorghum grain and its origin includes IS12697 (Australia), IS20697, IS715 (USA), IS23992 (Republic of Yemen), IS24462 (South Africa), IS30466 (China), IS30508 (Republic of Korea). The crop was harvested at the panicle (ear head) maturity stage. Panicles were threshed for grain and $250 \mathrm{~g}$ grain was used for experimental purpose. Whole grain was stored at $4^{\circ} \mathrm{C}$ for 30 days before extraction.

\section{Extraction of Total Phenols}

$5 \mathrm{~g}$ grain samples were ground to fine flour in UDY cyclone sample mill (UDY corporation, USA) to a particle size of $40 \mu \mathrm{m}$ separately. One gram of grain flour was mixed with $2.5 \mathrm{ml}$ of methanol with concentrated hydrochloric acid (v/v 99:1) and mixed well in incubator shaker for 1 hour at room temperature. The solution was centrifuged at $5000 \mathrm{~g}$ for $10 \mathrm{~min}$. The extraction process was repeated twice and the pooled extract was kept at $4^{\circ} \mathrm{C}$.

\section{Estimation of Total phenols}

Total phenolic content was determined by Folin-Ciocalteu (FC) method which was adapted from [10] with some modifications. The $125 \mu \mathrm{L}$ of extract, $400 \mu \mathrm{L}$ of methanol, $75 \mu \mathrm{L}$ of $2 \mathrm{~N}$ FCP reagent and 400 $\mu \mathrm{L}$ of $20 \% \mathrm{Na}_{2} \mathrm{CO}_{3}$ were combined in a plastic vial and then mixed well using a vortex. The mixture was allowed to react for $15 \mathrm{~min}$ then $1250 \mu \mathrm{L}$ of Millipore water was added and mixed well. The solution was centrifuged at $5000 \mathrm{rpm}$ for $15 \mathrm{~min}$ in refrigerated centrifuge at $10^{\circ} \mathrm{C}$ (Thermo Scientific ${ }^{\mathrm{TM}}$ Sorvall ${ }^{\mathrm{TM}} \mathrm{RC}$ 6 plus, Thermo Scientific corporation, USA). The absorbance was measured at $725 \mathrm{~nm}$ using a UV visible spectrophotometer (Model 1601, Shimadzu Corporation, Japan) and the results were expressed in gallic acid equivalents (GAE; $m \mathrm{~g} / \mathrm{kg}$ flour) using a gallic acid $(1.25-12.5 \mu \mathrm{g} / \mathrm{mL})$ standard curve. 


\section{Determination of Antioxidant Activity}

The antioxidant activity was determined using DPPH invitro assay method [11], $1 \mathrm{~mL}$ of 100 fold diluted sample extract and $1.5 \mathrm{~mL}$ of $0.25 \mathrm{mM} \mathrm{DPPH}$ was mixed well. The reaction mixture was then allowed to react for $30 \mathrm{~min}$. The absorbance was measured at $517 \mathrm{~nm}$ using a UV visible spectrophotometer (Model 1601,Shimadzu Corporation, Japan) and the results were expressed in ascorbic acid equivalents (AAEQ units/g flour) using ascorbic acid (10-50 $\mu \mathrm{g} / \mathrm{mL})$ standard curve.

\section{UFLC profiling of phenolic acids}

The concentration of specific phenolic acid analysis was carried out with a UFLC system (LC 20AD, Shimadzu corporation, Japan) equipped with a photo diode array (PDA) detector (SPD, M20A, Schimadzu Corporation, Japan). Polyphenols separation was done using a reversed phase $\mathrm{C}_{18}$ column (4.6 x 250 $\mathrm{mm}, 100 \mathrm{~A}, 5 \mu \mathrm{m}$ particle size, Phenomenex, India). A gradient binary mobile phase consisting of $0.1 \%$ phosphoric acid $(v / v)$ as solvent $\mathrm{A}$ and acetonitrile in solvent $\mathrm{B}$ at a flow rate of $1.2 \mathrm{~mL} / \mathrm{min}$ was used with initial A: B ratio of $90: 10$ for $13 \mathrm{~min}$, then a linear gradient increase of B solvent to $40 \%$ from 13 to 14 min followed by a 3 min hold time and a linear gradient back to the initial A: B ratio of 90:10 in 1 min. Finally an equilibration step with initial concentration for $5 \mathrm{~min}$ for a total run time of 22 minutes detection and tentative identification of specific phenolic acid analysis was carried out using the diode array data between 210 to $700 \mathrm{~nm}$ along with their retention times and the concentrations were expressed in terms of $\mathrm{mg} / \mathrm{gm}$ of flour [12].

\section{STATISTICAL ANALYSIS}

All experiments were carried out in triplicates and data were reported as mean \pm standard deviation. Statistical software Indostat, version, 2.0 for ANOVA and Microsoft Excel, 2010 for correlations were used respectively. The differences of mean values among sorghum samples were determined by one-way analysis of variance (ANOVA) followed by Tukey's honestly significant difference (HSD) multiple rank tests at $\mathrm{p} \leq 0$ .05 , significance level.

\section{RESULTS AND DISCUSSION \\ Variability of total phenolic content (TPC) in white, red and brown colour sorghum genotypes}

The total phenolic content of 38 white, 15 red, 7 brown pericarp sorghum genotypes was determined and the results were presented in the Tables 1, 2, 3 respectively. Based on the experimental analysis total phenolic content was in the range of 575.05 to 3161.87 $\mathrm{mg}$ GAE $/ \mathrm{kg}$. The genotype IS31681 had the highest total phenolic content and the AKR150 had the lowest total phenol content. Based on the statistical analysis of the total phenolic content, the genotype IS31681 is significantly different (at CD 1\%) from the rest of the white pericarp grains sorghum genotypes tested (Table1). The present findings are in accordance with [13] who reported a similar range of variation (1.35- 37.73 mg GAE $\mathrm{g}^{-1} \mathrm{dm}^{-1}$ ) in 224 sorghum samples. [14] have reported that total phenolic content in whole sorghum flour (8.33 mg. $\left.\mathrm{g}^{-1}\right)$, decorticated sorghum flour (1.44 $\left.\mathrm{mg} . \mathrm{g}^{-1}\right)$ and sorghum bran $\left(31.95 \mathrm{mg} \cdot \mathrm{g}^{-1}\right)$ of the genotype SC 21. [15] have reported total phenolic content in 36 light colored sorghum lines ranges between 0.60 to $20.73 \mathrm{~g} \mathrm{GAE} \mathrm{kg}^{-1} \mathrm{dm}^{-1}$. This represents phenolic compounds are quality grade markers for the preparation of several foods due to their enzyme inhibitory activities [16]. The present findings were in agreement with Glennie who reported that concentrations of total phenols of white sorghum grains ranged from 80 to $100 \mathrm{mg} / 100 \mathrm{~g}$, by [17] is from 109.21 to $116.70 \mathrm{mg} / 100 \mathrm{~g}$.

Table-1: Total phenolic content and DPPH radical scavenging activity of white pericarp sorghum genotypes

\begin{tabular}{|l|l|l|l|}
\hline S.No & \multicolumn{1}{|c|}{ Genotype } & \multicolumn{1}{|c|}{ TPC $(\mathbf{m g} / \mathbf{k g})$} & \multicolumn{1}{c|}{$\begin{array}{c}\text { DPPH RSA } \\
\text { (mg AEQ } / \mathbf{k g})\end{array}$} \\
\hline 1 & $\mathbf{2 7 B}$ & $864.9 \pm 1.92$ & $5579.06 \pm 39.91$ \\
\hline 2 & $\mathbf{2 9 6 B}$ & $814.9 \pm 2.27$ & $4073.85 \pm 86.11$ \\
\hline 3 & 463B & $722.5 \pm 3.11$ & $3820.78 \pm 98.41$ \\
\hline 4 & 7B & $1020.1 \pm 3.17$ & $4980.45 \pm 34.92$ \\
\hline 5 & AKMS14B & $749.7 \pm 0.00$ & $4799.74 \pm 293.97$ \\
\hline 6 & AKR150 & $575.0 \pm 2.95$ & $4471.58 \pm 191.90$ \\
\hline 7 & AKR354 & $736.6 \pm 3.54$ & $4113.53 \pm 182.06$ \\
\hline 8 & C43 & $677.4 \pm 2.67$ & $4748.45 \pm 176.95$ \\
\hline 9 & CSV13 & $719.2 \pm 3.36$ & $5984.71 \pm 291.02$ \\
\hline 10 & CSV15 & $755.5 \pm 3.63$ & $6058.80 \pm 186.24$ \\
\hline 11 & IC 345194 & $715.6 \pm 4.53$ & $5691.94 \pm 0.00$ \\
\hline 12 & IC 305903 & $1008.3 \pm 2.07$ & $5167.85 \pm 0.00$ \\
\hline 13 & IC 305923 & $913.0 \pm 2.07$ & $4759.43 \pm 192.45$ \\
\hline 14 & I12 & $844.8 \pm 7.00$ & $5224.34 \pm 35.92$ \\
\hline 15 & IMS9B & $768.8 \pm 1.01$ & $4730.20 \pm 248.34$ \\
\hline 16 & IS31681 & $3161.8 \pm 4.08$ & $555.73 \pm 156.62$ \\
\hline 17 & IS33648 & $1147.6 \pm 1.04$ & $4193.61 \pm 91.16$ \\
\hline
\end{tabular}




\begin{tabular}{|l|l|l|l|}
\hline 18 & IS40751 & $821.4 \pm 3.63$ & $5587.34 \pm 167.90$ \\
\hline 19 & IS4372 & $1068.8 \pm 0.07$ & $3874.40 \pm 381.67$ \\
\hline 20 & RS627 & $872.4 \pm 3.54$ & $3657.40 \pm 0.00$ \\
\hline 21 & RS673 & $1159.8 \pm 0.98$ & $4784.65 \pm 218.87$ \\
\hline 22 & SPV1258 & $1414.5 \pm 2.72$ & $5235.85 \pm 96.16$ \\
\hline 23 & SPV1293 & $972.4 \pm 4.55$ & $5167.33 \pm 0.00$ \\
\hline 24 & SPV1471 & $924.8 \pm 2.70$ & $5481.45 \pm 98.13$ \\
\hline 25 & SPV1606 & $1043.8 \pm 1.52$ & $5976.56 \pm 106.99$ \\
\hline 26 & SPV1616 & $634.4 \pm 4.79$ & $5268.64 \pm 186.24$ \\
\hline 27 & SPV1731 & $795.4 \pm 4.66$ & $3324.33 \pm 127.08$ \\
\hline 28 & SPV1732 & $933.9 \pm 3.73$ & $3583.91 \pm 155.31$ \\
\hline 29 & SPV1733 & $843.0 \pm 0.49$ & $4078.12 \pm 44.71$ \\
\hline 30 & SPV1734 & $1001.5 \pm 6.88$ & $3557.68 \pm 970.63$ \\
\hline 31 & SPV1750 & $773.3 \pm 2.72$ & $3711.02 \pm 700.60$ \\
\hline 32 & SPV1760 & $1023.3 \pm 1.81$ & $3590.36 \pm 92.44$ \\
\hline 33 & SPV1775 & $857.0 \pm 3.45$ & $6017.38 \pm 0.00$ \\
\hline 34 & SPV459 & $926.6 \pm 4.43$ & $4290.07 \pm 83.84$ \\
\hline 35 & SPV462 & $876.4 \pm 4.15$ & $5943.52 \pm 0.00$ \\
\hline 36 & SPV711 & $1147.6 \pm 3.11$ & $4020.65 \pm 437.88$ \\
\hline 37 & SPV933 & $1118.5 \pm 5.60$ & $4468.50 \pm 64.64$ \\
\hline 38 & IS18035 & $1108.3 \pm 3.54$ & $5392.38 \pm 86.60$ \\
\hline & C.D. $(5 \%)$ & 57.10 & 520.25 \\
\hline & C.D. $(1 \%)$ & 76.52 & 697.22 \\
\hline & C.V. $\%)$ & 2.93 & 5.55 \\
\hline & F (Probability) & 0.00 & 0.00 \\
\hline & Results are expressed as mean \pm SD \\
\hline
\end{tabular}

The total phenolic content of the red pericarp sorghum genotypes (Table-2) is in the range of 888.33$4230 \mathrm{mg}$ GAE $/ \mathrm{kg}$. The genotype IS16151 had the highest total phenolic content followed by IS1212, IS30538 and IS29950, whereas genotype IS28141 showed lowest polyphenols (Table-2). Based on statistical analysis of the TPC, the first four genotypes such as IS16151, IS1212, IS30538 and IS29950 were significantly (at CD 1\%) different from each other as well as with the rest of the red pericarp sorghum genotypes tested. Shuyu S et al., [18] have reported the TPC in different sorghum varieties ranging from 174.40 to $1238.83 \mathrm{mg}$ GAE/100 g grain. The other reports supporting the present study showed sorghum with red pericarp at $3.38 \mathrm{mg} / \mathrm{g}$ GAE Khoddami et al., 2015 , QL33/QL36 (red) 0.88 TPC mg/g GAE, B923296 (red) $0.66 \mathrm{TPC} \mathrm{mg} / \mathrm{g}$ GAE [7] Generally the total polyphenol content in sorghum is affected by genetic and environmental factors, such as plant color, thickness of the pericarp, and growth conditions. Sorghum with red/purple color has higher total polyphenol contents than tan sorghum grains. The high polyphenol content in red sorghum contributes to a higher resistance to biotic and abiotic stress [19].

Table-2: Total phenolic content and DPPH radical scavenging activity of red pericarp sorghum genotypes

\begin{tabular}{|c|c|c|c|}
\hline S.No & Genotype & $\begin{array}{c}\text { TPC } \\
\text { (mg GAE/kg) }\end{array}$ & $\begin{array}{c}\text { DPPH RSA } \\
\text { (mg AAEQ } / \mathrm{kg})\end{array}$ \\
\hline 1 & IS1212 & $3707.8 \pm 5.91$ & $6259.32 \pm 70.52$ \\
\hline 2 & IS12706 & $1824.6 \pm 2.46$ & $6549.58 \pm 0.00$ \\
\hline 3 & IS12735 & $2078.8 \pm 5.91$ & $3566.85 \pm 250.83$ \\
\hline 4 & IS16151 & $4230.1 \pm 2.59$ & $1190.18 \pm 0.00$ \\
\hline 5 & IS20298 & $2078.1 \pm 8.85$ & $3908.60 \pm 367.84$ \\
\hline 6 & IS20743 & $1668.4 \pm 2.36$ & $2678.58 \pm 97.69$ \\
\hline 7 & IS23514 & $2754.1 \pm 1.97$ & $2431.30 \pm 350.14$ \\
\hline 8 & IS2389 & $1739.0 \pm 4.84$ & $4489.15 \pm 208.67$ \\
\hline 9 & IS28141 & $888.3 \pm 2.95$ & $3460.44 \pm 40.38$ \\
\hline 10 & IS28313 & $1072.5 \pm 3.48$ & $3517.55 \pm 121.15$ \\
\hline 11 & IS29241 & $3257.8 \pm 0.00$ & $2646.73 \pm 83.01$ \\
\hline 12 & IS29950 & $3342.9 \pm 5.33$ & $3304.38 \pm 232.11$ \\
\hline 13 & IS30538 & $3597.8 \pm 4.99$ & $2096.26 \pm 84.72$ \\
\hline 14 & IS3158 & $1768.8 \pm 6.38$ & $3746.02 \pm 210.83$ \\
\hline \multirow[t]{2}{*}{15} & IS4060 & $3163.5 \pm 5.66$ & $6204.58 \pm 146.37$ \\
\hline & C.D. $(5 \%)$ & 103.60 & 367.98 \\
\hline
\end{tabular}




\begin{tabular}{|l|c|l|l|}
\hline & C.D. (1\%) & 143.79 & 510.74 \\
\hline & C.V. (\%) & 1.95 & 4.59 \\
\hline & F (Probability) & 0.00 & 0.00 \\
\hline \multicolumn{2}{|c|}{ Results are expressed as mean + SD }
\end{tabular}

Similarly, the total phenolic content of the brown pericarp grain sorghum genotypes estimated was in the range of 1274.91-2885.72 $\mathrm{mg} \mathrm{GAE} / \mathrm{kg}$ (Table-3). The genotype IS12697 showed highest total phenolic content, where as IS24462 showed the lowest. As shown in the Table 3 the genotype IS12697 was significantly different from the remaining brown pericarp grain sorghum genotypes tested (at CD 1\%). This result is matching with the earlier reports of [7] who have reported that total phenolic content of brown pericarp IS13116 as $3.58 \mathrm{mg}$ GAE/g. In this study total phenolic content of sorghum genotypes is in the order of Red > white > brown. In addition, [20] investigated de-coated sorghum bran and found that the brown sorghum pericarp variety had higher TPC compared to the black pericarp, indicted the colour of pericarp may not be an ideal indicator of TPC.

Table-3: Total phenolic content and DPPH radical scavenging activity of brown pericarp sorghum genotypes

\begin{tabular}{|r|l|l|c|}
\hline \multicolumn{1}{|c|}{ S.NO } & \multicolumn{1}{|c|}{ Genotype } & $\begin{array}{c}\text { TPC } \\
\text { (mg GAE/kg) }\end{array}$ & $\begin{array}{c}\text { DPPH RSA } \\
\text { (mg AAEQ /kg) }\end{array}$ \\
\hline 1 & IS12697 & $2885.7 \pm 2.86$ & $20174.42 \pm 254.93$ \\
\hline 2 & IS20697 & $1510.35 \pm 3.63$ & $2896.39 \pm 210.34$ \\
\hline 3 & IS23992 & $1890.2 \pm 0.93$ & $2538.98 \pm 95.05$ \\
\hline 4 & IS24462 & $1274.9 \pm 6.60$ & $2929.62 \pm 198.25$ \\
\hline 5 & IS30466 & $1992.3 \pm 6.31$ & $4348.99 \pm 166.02$ \\
\hline 6 & IS30508 & $1626.1 \pm 3.63$ & $3635.48 \pm 670.70$ \\
\hline 7 & IS715 & $1907.8 \pm 5.47$ & $5494.40 \pm 159.64$ \\
\hline & C.D. (5\%) & 108.00 & 707.39 \\
\hline & C.D. (1\%) & 163.64 & 1071.79 \\
\hline & C.V. (\%) & 2.36 & 8.43 \\
\hline & F (Probability) & 0.00 & 0.00 \\
\hline
\end{tabular}

\section{DPPH radical scavenging activity}

Antioxidants are widely acknowledged for their action against damage by reactive oxygen species, which would be correlated to health beneficial properties such as anti-microbial, reduced oxidative stress, anti-inflammatory and anti-cancer activity [7]. Several methods have been developed including DPPH and ABTS radical scavenging methods. The DPPH radical, is widely used to evaluate the free radical scavenging activity of hydrogen donating antioxidants in many plant extracts [21]. Therefore, antioxidant capacity of sorghum grain was determined by using DPPH assay.

All values of DPPH radical scavenging activity of total phenolic fractions are expressed as milligrams of Ascorbic acid equivalent per gram of grains. The DPPH free radical scavenging activity of white, red and brown pericarp sorghum genotypes is shown in Tables 1, 2, 3 respectively. The results showed that the antioxidant activity of red coloured sorghum genotypes was significantly higher than that of white and brown pericarp sorghum genotypes. This is similar to the gradation of polyphenols Red > white > Brown. The estimated DPPH radical scavenging activity of white pericarp sorghum genotypes is in the range of 555.74-6058.80 $\mathrm{mg}$ AAEQ $/ \mathrm{kg}$ (Table-4). Similarly [18] have reported that white sorghum genotype such as Longmi sorghum has the DPPH RSA of $920 \mathrm{mg} \mathrm{AAEQ} / \mathrm{kg}$. Also, it was reported that, white sorghum had the antioxidant activity of $14 \mu \mathrm{mol} / \mathrm{g}$ (as ABTS) [22]. In the present study genotypes CSV15 and SPV1775 showed highest DPPH radical scavenging activity and genotype IS31681 had lowest. Based on the statistical analysis CSV15, SPV1775, CSV13, SPV1606, SPV462, IC345194, IS40751, 27 B, SPV1471 and IS18035 were found to be not significantly different from each other. However, CSV15 was significantly different from the remaining genotypes tested (at CD 1\%) (Table-1).

Similarly in red sorghum genotypes DPPH radical scavenging activity is shown in Table-2. The DPPH RSA estimated is in the range of 1190.19 $6549.59 \mathrm{mg} \mathrm{kg}^{-1}$ (Table-4). Of all the genotypes tested, high DPPH RSA is observed in IS12706, IS1212 and IS4060 and low is noted in IS16151. Based on the statistical analysis of the red pericarp sorghum genotypes IS12706, IS1212 and IS4060 were not significantly different from each other, however statistically significant difference was found from the rest of the genotypes (at CD 1\%) (Table-2). In four brewing sorghum varieties, DPPH RSA was reported includes Hongyingzi (19.05 mg AAEQ/g), Hongzhenzhu (5.31 mg AAEQ/g), Dongbei sorghum 
(14.94 mg AAEQ/g) and Jiangsu sorghum (1.61 mg $\mathrm{AAEQ} / \mathrm{g})$ [18].

Similarly DPPH radical scavenging activity of brown pericarp grain sorghum genotypes is shown in (Table-3), is in the range of 2174.43- $5494.40 \mathrm{mg}$ AAEQ kg-1 (Table-4). Of all the genotypes tested high DPPH RSA is observed in IS715 followed by IS30466 and low was noted in IS12697. Based on the statistical analysis of the brown pericarp sorghum genotypes IS715 is significantly different from the rest of the

Table-4: Mean values and range of total phenolic content a genotypes tested (at CD 1\%) (Table-3). In earlier literature it was found that non-pigmented sorghum showed relatively radical scavenging activity ranged from $7 \%$ to $67 \%$ [23], antioxidant capacity measured by ABTS assay of non-tannin sorghum grains ranged from 9.7-78.9 $\mu \mathrm{mol} \mathrm{TE} / \mathrm{g}$ sample [24]. To our knowledge, this data will add more information to the existing knowledge on the polyphenols, antioxidant activity, phenolic acid profiles of 60 different pericarp sorghum genotypes across the world, which is important for the selection of sorghums to be used for functional foods. genotypes

\begin{tabular}{|l|l|l|}
\hline & Total phenolic content (mg GAE/kg) & DPPH RSA (mg AAEQ /kg) \\
\hline White sorghum & & \\
\hline Mean \pm SD & $960.91 \pm 405.77$ & $4628.56 \pm 1063.27$ \\
\hline Range & $575.05-3161.87$ & $555.74-6058.80$ \\
\hline SE & 65.87 & 6.16 \\
\hline Red sorghum & & \\
\hline Mean \pm SD & $2478.22 \pm 1024.41$ & $3736.62 \pm 1569.59$ \\
\hline Range & $888.33-4230.14$ & $1190.19-6549.59$ \\
\hline SE & 264.7 & 104.63 \\
\hline Brown sorghum & & \\
\hline Mean \pm SD & $1726.03 \pm 262.92$ & $3431.9 \pm 1158.59$ \\
\hline Range & $1274.91-1992.39$ & $2174-5494.40$ \\
\hline SE & 99.59 & 165.51 \\
\hline
\end{tabular}

UFLC Identification and quantification of phenolic acids in white, red and brown pericarp grain sorghum genotypes

Sorghum grain contains phenolic acids, which are located in the pericarp, testa, aleurone layer and endosperm [25]. Sorghum rich in phenols with antioxidant properties is important to identify the individual phenolic compounds, which could allow the sorghum genotype selection and grains production system to provide help in health, food, nutraceutical and pharmaceutical applications [26].

White, red and brown pericarp sorghum genotypes with high phenolic content were selected and analysed for phenolic acids through UFLC. The analysis by UFLC-DAD acidified methanolic extracts revealed the presence of different classes of phenolic acids. The UFLC profile of all these 11 phenolic compounds when taken together showed the same sequence of elution using this method and were confirmed by comparison of retention times, UV spectral data with those of commercial standards (Figure 1a, 1b, 1c). Chromatogram of 11 standard phenolic compounds showing namely gallic acid (5.19 min), salicin (7.8 min), catechin (10.77 min), 4-hydroxy benzoic acid (10.91 min), vanillic acid (13.49 $\mathrm{min})$, chlorogenic acid (12.73), caffeic acid (15.2 min), syringic acid (16 min), ferulic acid (18.68), salicylic acid (19.57 $\mathrm{min})$ and cinnamic acid (21.5 min) which were eluted at different retention times. Each phenolic acid identified in white, red and brown pericarp grain sorghum genotypes are quantified and presented in Table $6 \mathrm{a}, 6 \mathrm{~b}$ and $6 \mathrm{c}$ respectively.

Among the 38 white sorghum genotypes only eleven genotypes IS31681, SPV1258, RS673, SPV711, IS 33648, SPV 1732, IC 305923, IS40751, 296B, IMS 9B, IC 345194 rich in total phenolic content were selected and quantified for individual phenolic acids (table 5a). In white sorghum genotypes gallic acid $(0.64-76.6 \mathrm{mg} / 100 \mathrm{~g})$, vanillic acid $(0.15-5.5$ $\mathrm{mg} / 100 \mathrm{~g})$, chlorogenic acid (2.22 to $6.64 \mathrm{mg} / 100 \mathrm{~g}$ ), ferulic acid (1.7 to $7.52 \mathrm{mg} / 100 \mathrm{~g})$, salicylic acid $(8.95$ to $32.2 \mathrm{mg} / 100 \mathrm{~g})$, catechin $(2.55$ to $9.2 \mathrm{mg} / 100 \mathrm{~g}$ ) and caffeic acid $(0.56$ to $18.44 \mathrm{mg} / 100 \mathrm{~g})$ were identified. Higher content of gallic acid was detected only in SPV711 genotype, whereas, vanillic acid was detected in IS33648, chlorogenic acid in SPV1258, Ferulic acid in IC305923, salicylic acid in IS31681, catechin was detected only in SPV1258 and caffeic acid was detected only in SPV1258 (Table-6a). Similarly, White pericarp sorghum variety CS3541 was reported to have the phenolic compounds such as gallic acid, phydroxybenzoic acid, vanillic acid, protocatechuic acid, coumaric acid, caffeic acid, ferulic acid and cinnamic acid [19].

Table-6a: Phenolic acids quantified in methanolic extracts of white pericarp grain sorghum genotypes (by elution order)

\begin{tabular}{|c|c|c|c|c|c|c|c|c|}
\hline Genotype & Gallic acid & Vanillic acid & Chlorogenic acid & Ferulic acid & Salicylic acid & Catechin & Caffiec acid & $\begin{array}{l}\text { Total phenolic } \\
\text { acids } \\
(\mathrm{mg} / \mathbf{1 0 0 g})\end{array}$ \\
\hline IS31681 & n.d. & n.d. & n.d. & n.d. & $32.2 \pm 0.14$ & n.d. & n.d. & 32.2 \\
\hline
\end{tabular}




\begin{tabular}{|l|l|l|l|l|l|l|l|l|}
\hline SPV1258 & $12.3 \pm 0.42$ & n.d. & $6.64 \pm 0.19$ & n.d. & n.d. & $9.2 \pm 0.04$ & $18.44 \pm 0.33$ & 46.58 \\
\hline RS673 & $0.63 \pm 0.00$ & $0.15 \pm 0.00$ & n.d. & n.d. & n.d. & $2.55 \pm 0.01$ & n.d. & 3.33 \\
\hline SPV711 & $76.6 \pm 0.42$ & n.d. & n.d. & n.d. & n.d. & n.d. & n.d. & 76.6 \\
\hline IS33648 & n.d. & $5.5 \pm 0.28$ & n.d. & $7.45 \pm 0.3$ & n.d. & n.d. & n.d. & 12.95 \\
\hline SPV 1732 & n.d. & $1.5 \pm 0.4$ & $2.85 \pm 0.06$ & $3.61 \pm 0.4$ & n.d. & n.d. & n.d. & 7.96 \\
\hline IC 305923 & $0.64 \pm 0.04$ & $0.42 \pm 0.03$ & n.d. & $7.52 \pm 0.1$ & n.d. & n.d. & $0.56 \pm 0.02$ & 9.14 \\
\hline IS40751 & n.d. & $0.63 \pm 0.04$ & $2.22 \pm 0.16$ & $4.06 \pm 0.08$ & $8.95 \pm 0.07$ & n.d. & n.d. & 15.86 \\
\hline 296B & n.d. & $0.74 \pm 0.05$ & n.d. & $1.8 \pm 0.14$ & n.d. & n.d. & n.d. & 2.54 \\
\hline IMS 9B & n.d. & $1.2 \pm 0.28$ & $5.3 \pm 0.13$ & $1.77 \pm 0.17$ & n.d. & n.d. & n.d. & 8.28 \\
\hline IC 345194 & n.d. & $1.85 \pm 0.07$ & $6.26 \pm 0.19$ & $3.62 \pm 0.38$ & n.d. & n.d. & n.d. & 11.73 \\
\hline
\end{tabular}

Values are calculated from the area obtained for each compound and for each authentic standards. Results are expressed as mean $\pm \mathrm{SD}$, n.d-notdetected.

Among the 15 red pericarp sorghum genotypes only eight genotypes rich in total phenolic content, which includes IS1212, IS16151, IS28313, IS29950, IS29241, IS3158, IS30538 and IS4060, were quantified for phenolic acids through UFLC. In red pericarp sorghum genotypes the phenolic acids detected were gallic acid $(7.4 \mathrm{mg} / 100 \mathrm{~g})$, salicylic acid (28.67 $\mathrm{mg} / 100 \mathrm{~g})$, protocatechuic acid $(12.85 \mathrm{mg} / 100 \mathrm{~g})$, salicin (1.55 to $44.55 \mathrm{mg} / 100 \mathrm{~g})$, vanillic acid $(0.20$ to $1.21 \mathrm{mg} /$ $100 \mathrm{~g}$ ), chlorogenic acid ( 0.82 to $4.5 \mathrm{mg} / 100 \mathrm{~g}$ ), ferulic acid ( 2.6 to $49.7 \mathrm{mg} / 100 \mathrm{~g}$ ) and catechin $(1.05 \mathrm{mg} /$ $100 \mathrm{~g}$ ) (Table-6b). This holds true with the earlier reports where red sorghum variety SC0630 was reported to have the phenolic compounds such as gallic acid, p-hydroxybenzoic acid, vanillic acid, protocatechuic acid, coumaric acid, caffeic acid, ferulic acid and cinnamic acid [19] Of all the phenolic acids observed, only ferulic acid was identified at higher concentration compared to other phenolic compounds in the red grain sorghum genotypes, of which IS29950 showed high content of $t$-ferulic acid $(49.75 \mathrm{mg} / 100 \mathrm{~g}$ flour). which is akin to the earlier reports where phenolic acids in the red sorghum variety PAN 3860 were identified include ferulic acid as the major compound followed by protocatechuic acid, protocatechuic aldehyde, caffeic acid and p-coumaric acid [27].

Similarly high total phenolic content containing brown pericarp grain sorghum genotypes, which includes IS12697, IS30466, IS715, IS23992 and IS30508, were evaluated for phenolic acids. The identified phenolic acids were gallic acid (2.85 to 11.58 $\mathrm{mg} / 100 \mathrm{~g})$, 4-hydroxy benzoic acid (0.57 mg/ 100g), vanillic acid $(0.45 \mathrm{mg} / 100 \mathrm{~g})$, salicylic acid $(0.94 \mathrm{mg} /$ $100 \mathrm{~g})$ and catechin $(25.5 \mathrm{mg} / 100 \mathrm{~g})$ (Table -6c). High phenolic acid content was noted in IS30508 (32.03 mg/ $100 \mathrm{~g})$ followed by IS30466 and IS715 (11.3 mg/ 100g). Similar conclusions have been made in brown color sorghum variety (SC0719) was reported to have the phenolic compounds such as gallic acid, phydroxybenzoic acid, vanillic acid, protocatechuic acid, coumaric acid, caffeic acid, ferulic acid and cinnamic acid [19].

Table-6b: Phenolic acids quantified in methanolic extracts of red pericarp sorghum genotypes (by elution order)

\begin{tabular}{|c|c|c|c|c|c|c|c|c|c|}
\hline Genotype & $\begin{array}{l}\text { Gallic } \\
\text { acid }\end{array}$ & $\begin{array}{l}\text { Salicylic } \\
\text { acid }\end{array}$ & $\begin{array}{l}\text { Protocatechuic } \\
\text { acid }\end{array}$ & Salicin & $\begin{array}{l}\text { Vanilic } \\
\text { acid }\end{array}$ & $\begin{array}{l}\text { Chlorogenic } \\
\text { acid }\end{array}$ & Ferulic acid & Catechin & $\begin{array}{l}\text { Total } \\
\text { phenolic } \\
\text { acids } \\
\text { mg/100g }\end{array}$ \\
\hline IS16151 & n.d. & $28.67 \pm 0.43$ & n.d. & n.d. & n.d. & n.d. & n.d. & n.d. & 28.67 \\
\hline IS1212 & n.d. & n.d. & n.d. & n.d. & n.d. & n.d. & n.d. & $1.05 \pm 0.09$ & 1.05 \\
\hline IS30533 & $\begin{array}{ll}7.41 & \pm \\
0.02 & \\
\end{array}$ & n.d. & $12.85 \pm 0.07$ & n.d. & n.d. & n.d. & n.d. & n.d. & 20.26 \\
\hline IS29950 & n.d. & n.d. & n.d. & n.d. & n.d. & n.d. & $49.75 \pm 0.21$ & n.d. & 49.75 \\
\hline IS29241 & n.d. & n.d. & n.d. & $1.55 \pm 0.35$ & n.d. & n.d. & $2.60 \pm 0.28$ & n.d. & 4.15 \\
\hline IS4060 & n.d. & n.d. & n.d. & $44.55 \pm 0.49$ & n.d. & n.d. & n.d. & n.d. & 44.55 \\
\hline IS28313 & n.d. & n.d. & n.d. & n.d. & $1.21 \pm 0.01$ & $4.5 \pm 0.28$ & $10.65 \pm 0.07$ & n.d. & 16.36 \\
\hline IS3158 & n.d. & n.d. & n.d. & n.d. & $0.20 \pm 0.02$ & $0.82 \pm 0.05$ & $2.65 \pm 0.21$ & n.d. & 3.67 \\
\hline
\end{tabular}

Values are calculated from the area obtained for each compound and for each authentic standards. Results are expressed as mean $\pm \mathrm{SD}$, n.d. - not detected

Table-6c: Phenolic acids quantified in methanolic extracts of brown pericarp grain sorghum genotypes

\begin{tabular}{|l|l|l|l|l|l|l|}
\hline Genotype & Gallic acid & $\begin{array}{l}\text { 4-Hydroxy } \\
\text { benzoic acid }\end{array}$ & Salicylic acid & Catechin & Vanillic acid & $\begin{array}{l}\text { Total phenolic acids } \\
\text { (mg/100g) }\end{array}$ \\
\hline IS12697 & $2.85 \pm 0.07$ & n.d. & n.d. & n.d. & n.d. & 2.85 \\
\hline IS30466 & $11.58 \pm 0.40$ & n.d. & n.d. & n.d. & n.d. & 11.58 \\
\hline IS715 & $6.88 \pm 0.14$ & $0.57 \pm 0.01$ & $0.94 \pm 0.04$ & n.d. & n.d. & 8.39 \\
\hline IS23992 & ND & n.d. & n.d. & n.d. & $0.45 \pm 0.07$ & 0.45 \\
\hline IS30508 & $6.78 \pm 0.26$ & n.d. & n.d. & $25.25 \pm 0.77$ & n.d. & 32.03 \\
\hline
\end{tabular}

n.d. - not detected. 
Values are calculated from the area obtained for each compound and for each authentic standards. Results are expressed as mean $\pm \mathrm{S}$

The chromatograms are given for the genotype SPV1258 (white sorghum) rich in caffeic acid (RT 12.9 min), IS29950 (red sorghum) rich in ferulic acid (RT $18.68 \mathrm{~min}$ ) and IS30466 (brown sorghum) rich in gallic acid (RT 3.5 min) (Figure 1a, 1b, 1c). Ferulic acid has been reported as the most abundant bound phenolic compound in sorghum [25] and other cereals. The contents of ferulic acid in bound fractions in the investigated sorghum grains also showed the highest level compared to other phenolic acids, accounted for over $60 \%$ of the total identified phenolic acids and ranged from 1.55 to $85.98 \mathrm{mg} / 100 \mathrm{~g}$ grain (DW). The concentration of ferulic acid $(86.84 \mathrm{mg} / 100 \mathrm{~g})$ in black gain sorghum was higher than the reported levels in sorghum grains, oat, rice, wheat and barley $(8,17,23)$. Total concentrate caffeic acid varied from 3.49 to 8.17 $\mathrm{mg} / 100 \mathrm{~g}$ grain [18]. Similar levels were reported before in other varieties of sorghums [28].

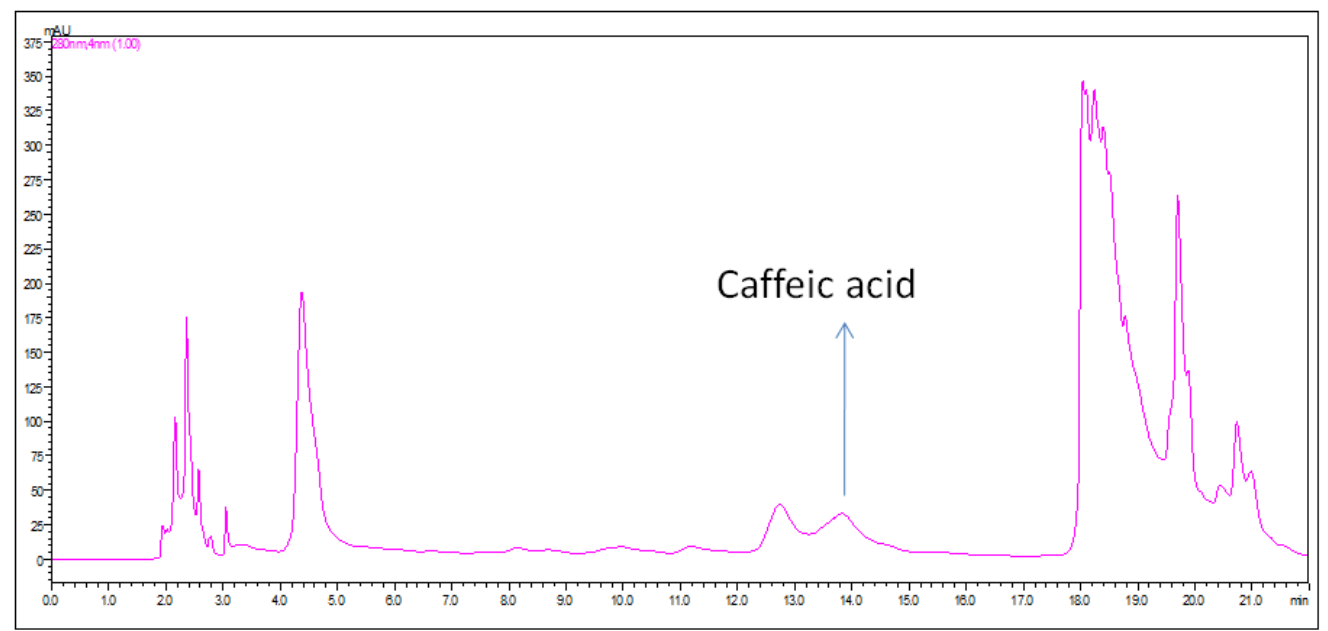

Fig-1a: UFLC Chromatogram of SPV1258 white sorghum genotype rich in caffeic acid eluted at RT 12.9 min

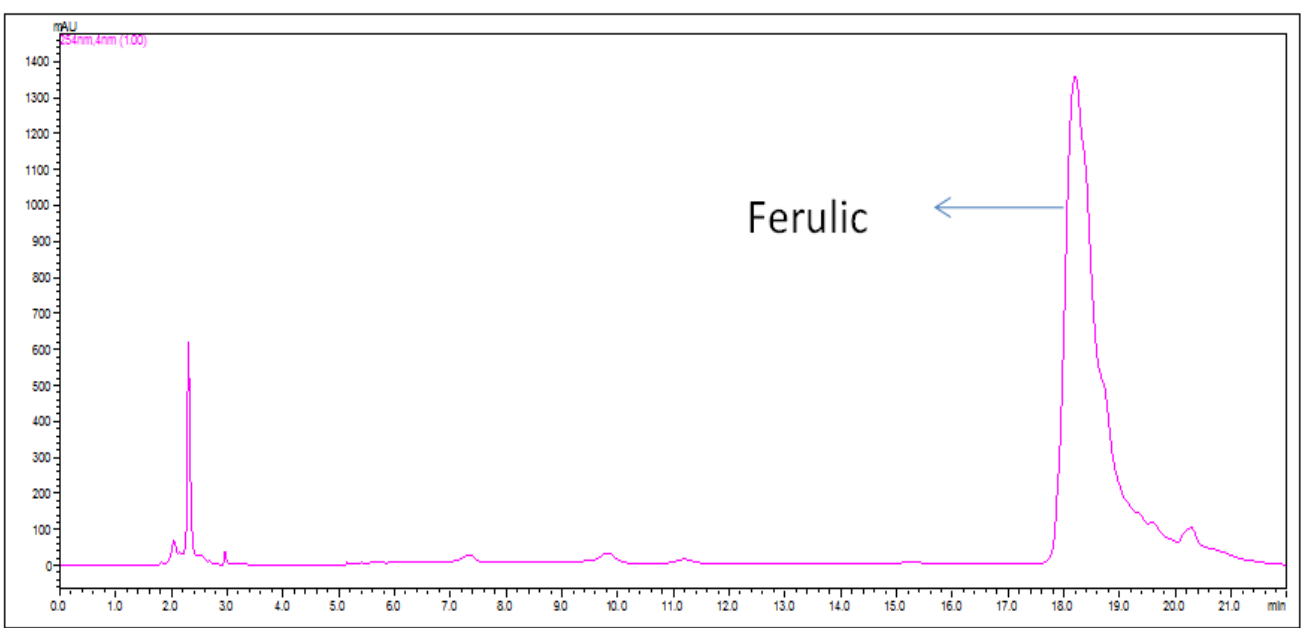

Fig-1b: UFLC Chromatogram of IS29950 red sorghum genotypes ferulic acid eluted at RT $18.68 \mathrm{~min}$ 


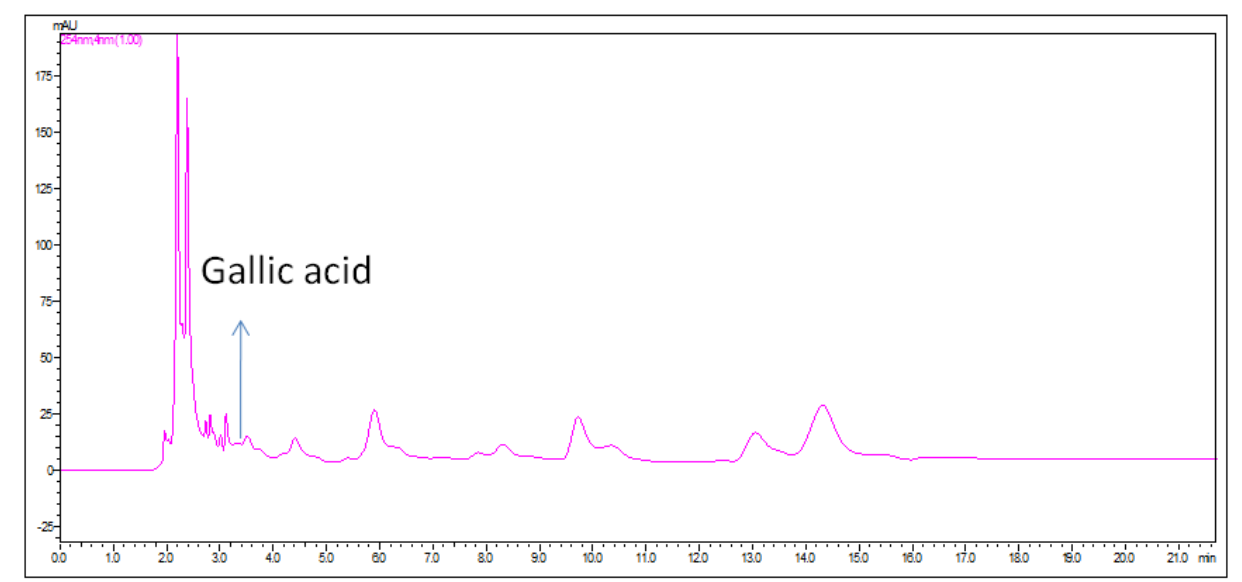

Fig-1c: UFLC Chromatogram of IS30466 brown sorghum genotype rich in gallic acid eluted at RT 3.5 min

Sorghum is a good source of phenolic compounds. Gallic acid was present only in the bound form where as protocatechuic, p-hydroxybenzoic, caffeic, $p$-coumaric and ferulic acids were found in the free and bound forms. However, cinnamic and vanillic acids were found in the free and/or bound forms only in some sorghum varieties. Two sorghum genotypes namely white (PR6E6) and red (PR6E14) showed four phenolic acids (caffeic, $p$-coumaric, ferulic and sinapic acids) [29]. In general phenolic acids are bioaccessible, they have bioactivities and serve as potential natural sources of antioxidants in food and biological systems. Earlier literature have suggested that phenolic acids such as ferulic acid, cinnamic acid, p-hydroxybenzoic acid play a major role in inhibiting the growth of several fungal species [30].

Antioxidant capacities and their correlation with phenolic compounds

A negative correlation was found between poly phenolic content and DPPH Radical scavenging activity in white sorghum ( $\mathrm{r}$ value being -0.589), red sorghum ( $\mathrm{r}$ value being -0.202) and brown sorghum ( $\mathrm{r}$ value being -0.111) (Table-5). This result is in accordance with the reports of [31] who did not find a correlation between phenols and antioxidant activity, simply because they used only white sorghums, which are quite low in phenols. However these findings are in contrast to those of the earlier reports where the total phenol content of sorghums is significantly correlated with antioxidant activity $[16,19,32]$.

Table-5: Correlation between Total phenolic content and DPPH radical scavenging activity of white, red and brown pericarp sorghum genotypes

\begin{tabular}{|l|l|}
\hline & TPC \\
\hline White sorghum & \\
\hline Polyphenols & 1 \\
\hline DPPH & -0.589924309 \\
\hline Red sorghum & \\
\hline Polyphenols & 1 \\
\hline DPPH & -0.202780306 \\
\hline Brown sorghum & \\
\hline TPC & 1 \\
\hline DPPH & -0.111554331 \\
\hline
\end{tabular}

\section{CONCLUSION}

Comparison of the differences in total phenolic content and antioxidant capacities of different varieties of sorghum grains are reported in the present study. Red pericarp sorghums grains showed high phenolic as well as in vitro antioxidant activity. All of the sorghum grains contained high contents of phenolic acids, especially ferulic acid. It is therefore important to consider the genotype while selecting sorghums for human food and animal feed so as to obtain maximum energy and protein availability and they can be used as high antioxidant value-added health foods having nutraceutical or pharmaceutical applications. The results presented in this study will be of significant use to cereal producers and consumers as phenolic acids are known to influence the organoleptic properties and health benefits of whole grains.

\section{ACKNOWLEDGEMENTS}

The authors wish to acknowledge the financial support from Department of Biotechnology (DBT), New Delhi, India, in carrying out these investigation

\section{REFERENCES}

1. Sosa, V., Moliné, T., Somoza, R., Paciucci, R., Kondoh, H., \& LLeonart, M. E. (2013). Oxidative stress and cancer: an overview. Ageing research reviews, 12(1), 376-390.

2. Kunwar, A., \& Priyadarsini, K. I. (2011). Free radicals, oxidative stress and importance of antioxidants in human health. $J$ Med Allied Sci, 1(2), 53-60.

3. Woo, K. S., Lee, J.S., Ko, J. Y., Song, S. B., Seo, H. I., Seo, M.C., Oh, B. G., Kwak, D. Y., Nam, M. H., Oh, I. S., \& Jeong, H. S. (2012). Antioxidant compounds and antioxidant activities of different varieties of foxtail millet and proso millet according to cultivation time. Journal of the Korean Society of Food Science and Nutrition, 41, 302-9.

4. Sreeramulu, D., Reddy, C., \& Raghunath, M. (2009). Antioxidant activity of commonly 
consumed cereals, millets, pulses and legumes in India. Indian Journal of Biochemistry and Biophysics, 46, 112-115.

5. Vijaya Kumar Reddy, C., Sreeramulu, D., \& Raghunath, M. (2010). Antioxidant activity of fresh and dry fruits commonly consumed in India. Food Research International, 43, 285-288.

6. Akinoso, R., Lawal, I. A., \& Aremu, A. K. (2013). Energy requirements of size reduction of some selected cereals using attrition mill. International Food Research Journal, 20, 1205-1209.

7. Rao, S., Santhakumar, A. B., Chinkwo, K. A., Wu, G., Johnson, S. K., \& Blanchard, C. L. (2018). Characterization of phenolic compounds and antioxidant activity in sorghum grains. Journal of Cereal Science, 84, 103-111.

8. Ramatoulaye, F. M. C., Fallou, S., Amadou, K., \& Cyril, D. (2016). Production and use sorghum: A literature review. Journal of Nutritional Health Food Science, 4, 1- 4.

9. Awika, J. M., Rooney, L. W., WuX, Prior, R. L., \& Cisneros-Zevallos, L. (2003). Screening methods to measure antioxidant activity of sorghum (Sorghum bicolor) and sorghum products. Journal of Agricultural Food Chemistry, 51, 6657-6662.

10. Singleton, V. L. R., \& Orthofer LamuelaRaventos, R. M. (1999). Analysis of total phenols and other oxidation substrates and antioxidants by means of folin-ciocalteu reagent. Methods Enzymology, 299, 152-178.

11. Blois, M. S. (1958). Antioxidant determination by the use of a stable free radical. Nature, 181, 11991200 .

12. Antoanela, P., Ticuta, N. P., Cosmin, R., Mariana, A., Laura, B., \& Viorica, I. (2011). HPLC analysis of polyphenols and antioxidant capacity determination of Scirpusholoschoenus L. rhizome Ovidius University. Annals of Chemistry, pp, 6266.

13. Dykes, L., Rooney, W. L., \& Rooney, L. W. (2013). Evaluation of phenolics and antioxidant activity of black sorghum hybrids. Journal of Cereal Science, 58, 278-283.

14. Moraes, E. A., Marineli, R. D. S., Lenquiste, S. A., Steel, C. J., Menezes, C. B., Queiroz, V. A. V., \& Marostica Junior, M. R. (2015). Sorghum flour fractions: correlations among polysaccharides, phenolic compounds, antioxidant activity and glycemic index. Food Chemistry, 180, 116-123.

15. Alfieri, M., Balconi, C., Cabassi, G., Habyarimana, E., \& Redaelli, R. (2017). Antioxidant activity in a set of sorghum landraces and breeding lines. Maydica electronic publication, 62-M32.

16. Dicko, M. H., Gruppen, H., Traore, A. S., Van Berkel, W. J. H., \& Voragen, A. G. J. (2005). Evaluation of the effect of germination on phenolic compounds and antioxidant activities in sorghum varieties. Journal of Agricultural Food Chemistry, 53, 2581-2588.

17. Abd E-Moneim, M. R., Afify Hossam, S., ElBeltagi, Samiha, M., Abd El-Salam, Azza, A., \& Omran, (2012). Biochemical changes in phenols, flavonoids, tannins, vitamin E, $\beta$-carotene and antioxidant activity during soaking of three white sorghum varieties. Asian Pacific Journal of Tropical Biomedicine, 2, 203-209.

18. Shen, S., Huang, R., Li, C., Wu, W., Chen, H., Shi, J., ... \& Ye, X. (2018). Phenolic compositions and antioxidant activities differ significantly among sorghum grains with different applications. Molecules, 23(5), 1203.

19. Dykes, L., Rooney, L. W., Waniska, R. D., \& Rooney, W. L. (2005). Phenolic compounds and antioxidant activity of sorghum grains of varying genotypes. Journal of Agricultural Food Chemistry, 53, 6813-6818.

20. Awika, J. M., McDonough, C. M., \& Rooney, L. W. (2005). Decorticating sorghum to concentrate healthy phytochemicals. Journal of Agricultural Food Chemistry, 53, 6230-6234.

21. Kumar, M., Kumar, S., \& Kaur, S. (2011). Investigations on DNA protective and antioxidant potential of chloroform and ethyl acetate fractions of Koelreuteria paniculata Laxm. African Journal of Pharmacy and Pharmacology, 5, 421-427.

22. De Zacatares, V. R. C. (2007). Changes in quality of whole cooked sorghum [Sorghum bicolor (L.) Moench] using precooking methods (M.Sc. thesis) Food Science Technology Department, Texas University, 1-88.

23. Miller, H. E., Rigelhof, F., Marquart, L., Prakash, A., \& Kanter, M. (2000). Antioxidant content of whole grain breakfast cereals, fruits and vegetables. Journal of the American College of Nutrition, 19, 312S-319S.

24. Yang, L. (2009). Chemopreventive potential of sorghum with different phenolic profiles (M.Sc. thesis) Texas University, 1-117.

25. Hahn, D. H., Faubion, J. M., \& Rooney, L. W. (1983). Sorghum phenolic acids, their high performance liquid chromatography separation and their relation to fungal resistance. Cereal Chemistry, 60, 255-259.

26. Yousif, A., Nhepera, D., \& Johnson, S. (2012). Influence of sorghum flour addition on flat bread in vitro starch digestibility, antioxidant capacity and consumer acceptability. Food Chemistry, 134, 880-887.

27. Svensson, L., Sekwati-Monang, B., Lutz, D. L., Schieber, A., \& Ganzle, M. G. (2010). Phenolic acids and flavonoids in nonfermented and fermented red sorghum (Sorghum bicolor (L.) Moench). Journal of Agricultural and Food Chemistry, 58(16), 9214-9220.

28. Wu, G., Johnson, S. K., Bornman, J. F., Bennett, S. J., \& Fang, Z. (2017). Changes in whole grain polyphenols and antioxidant activity of six 
sorghum genotypes under different irrigation treatments. Food Chemistry, 214, 199-207.

29. Luthria, D. L., \& Liu, K, (2013). Localization of phenolic acids and antioxidant activity in sorghum kernels. Journal of Functional Foods, 5, 17511760.

30. Shahidi, F., \& Chandrasekara, A. (2013). Millet grain phenolics and their role in disease risk reduction and health promotion. A review. Journal of Functional Foods, 5, 570-581.
31. Kamath, V.G., Chandrashekar, A., \& Rajini, P. S. (2004). Antiradical properties of sorghum (Sorghum bicolor L. Moench) flour extracts. Journal of Cereal Science, 40, 283-288.

32. Awika, J. M., Rooney, L.W., Wu, X., Prior, R. L., \& Cisneros-Zevallos, L. (2003). Screening methods to measure antioxidant activity of sorghum (Sorghum bicolor) and sorghum products. Journal of Agricultural and Food Chemistry, 51, 6657-6662. 